\title{
Comparison of biomechanical behavior between a cast material torso jacket and a polyethylene based jacket
}

\author{
Robert Rizza ${ }^{*}$, XueCheng Liư ${ }^{2}$, John Thometz ${ }^{2}$, Channing J Tassone ${ }^{2}$ \\ From The 10th Meeting of the International Research Society of Spinal Deformities (IRSSD 2014 Sapporo) \\ Sapporo, Japan. 29 June - 2 July 2014
}

\section{Introduction}

Numerous designs are often used in the treatment of early onset of scoliosis. A Thoraco-Lumbo-Sacral Orthosis (TLSO) is constructed using Polyethylene (PE). A series of casting is implemented using cast material. The Cast material is less dense, allows the skin to breathe, and is made of a biodegradable water based resin $(3 \mathrm{M}$, BSN Medical). TLSO braces provide correction mechanically through constraint forces, which are minimized with excessive lateral defection.

\section{Objectives}

This study was motivated by goal to compare the biomechanical behavior of the cast based jacket with a PE based design.

\section{Materials and methods}

Samples of cast material (Delta-Cast Soft, BSN Medical) were tested for mechanical properties (Young's Moduli, Poisson ratio and shear modulus). The cast material is a composite material with properties varying in different directions (Figure 1). A finite element model of a patient's brace was created using an optical scan of the brace. The number of layers in the cast model was varied to determine the number of optimal layers. For the PE, a thickness of $4 \mathrm{~mm}$ was used. Loads applied to the brace by the torso were held constant and the lateral defection determined.

\section{Results}

The simulations indicate that the cast jacket with 6 layers will generate at most $4.7 \mathrm{~mm}$ deformation. The

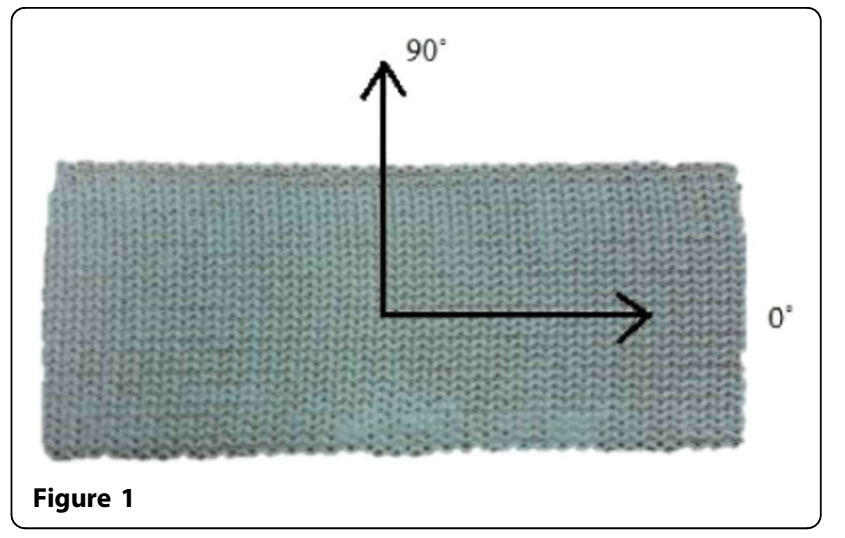

PE brace will generate a deformation of $2 \mathrm{~mm}$ (Figure 2 ). The structural factor of safety (FOS) for the cast brace was found to be 5.71 and 2.70 for the PE design. The mass of the cast design was $0.175 \mathrm{~kg}$ compared to $0.643 \mathrm{~kg}$ for the PE design. Material costs for the cast design would be $\$ 25.95$ and for the PE design $\$ 51.90$.

\section{Conclusions}

Both designs will generate the proper constraint forces to maintain spinal correction. Based on the design parameters (thickness, mechanical properties, FOS and cost) the brace made of cast material, though slightly thicker ( $6.6 \mathrm{~mm}$ compared to $4 \mathrm{~mm}$ ) would be 3.5 times lighter and cost half as much (based on material costs). Furthermore the cast brace has double the strength. Thus, from the biomechanical point of view, the cast brace is more efficient than the PE brace.

${ }^{1}$ Dept. of Mechanical Engineering, Milwaukee School of Engineering

Milwaukee, WI, USA

Full list of author information is available at the end of the article 


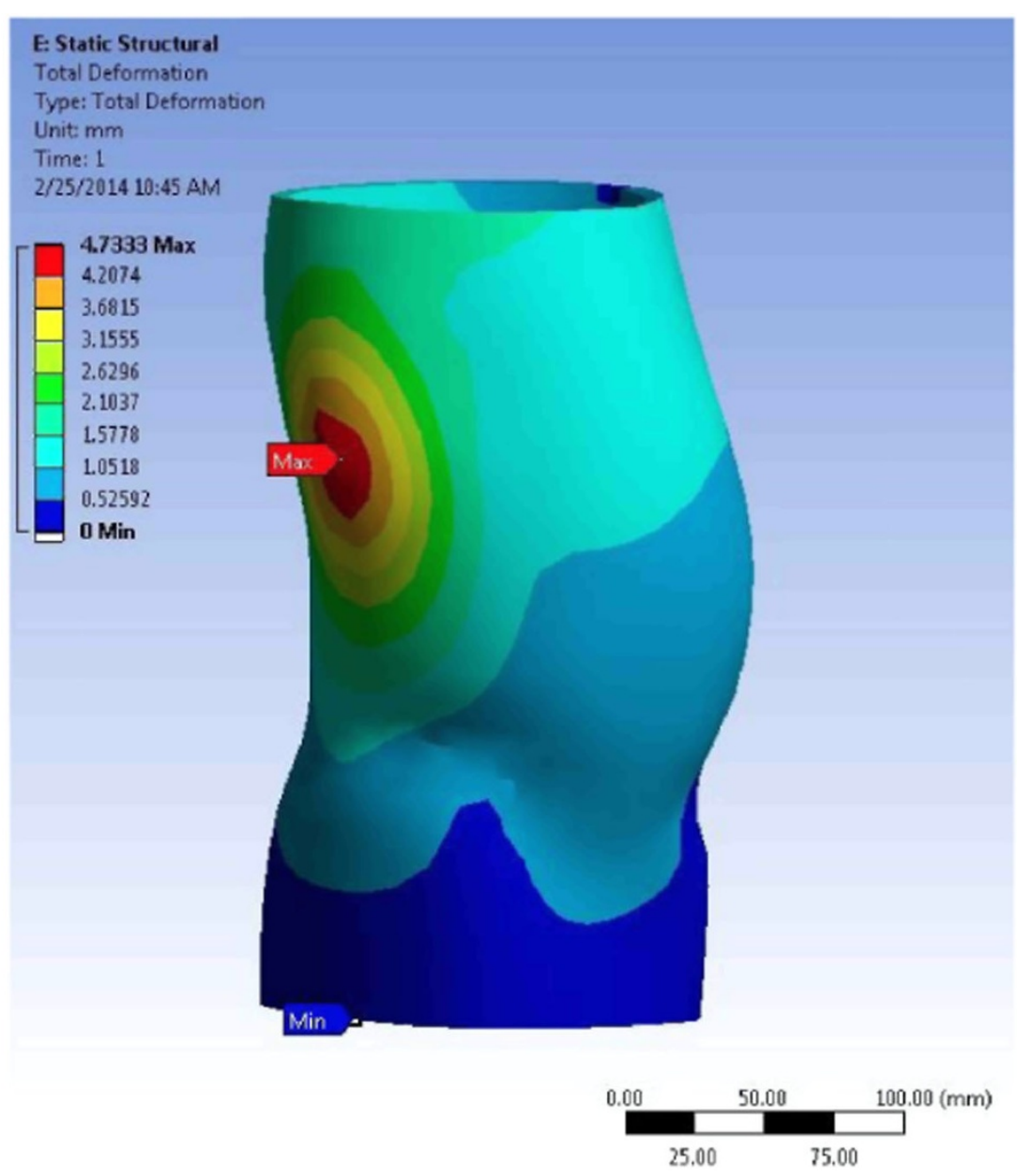

Figure 2

\section{Authors' details}

'Dept. of Mechanical Engineering, Milwaukee School of Engineering

Milwaukee, WI, USA. ${ }^{2}$ Department of Orthopaedic Surgery, Medical College

of Wisconsin, WI, USA.

Published: 19 January 2015

\section{Submit your next manuscript to BioMed Central} and take full advantage of:

- Convenient online submission

- Thorough peer review

- No space constraints or color figure charges

- Immediate publication on acceptance

- Inclusion in PubMed, CAS, Scopus and Google Scholar

- Research which is freely available for redistribution

Submit your manuscript at www.biomedcentral.com/submit 